\title{
Intercomparison of peroxy radical measurements obtained at atmospheric conditions by laser-induced fluorescence and electron spin resonance spectroscopy
}

\author{
H. Fuchs ${ }^{1}{ }^{*}$, T. Brauers ${ }^{1}$, R. Häseler ${ }^{1}$, F. Holland ${ }^{1}$, D. Mihelcic ${ }^{1}$, P. Müsgen ${ }^{1}$, F. Rohrer ${ }^{1}$, R. Wegener ${ }^{1}$, and \\ A. Hofzumahaus ${ }^{1}$ \\ ${ }^{1}$ Institut für Chemie und Dynamik der Geosphäre 2, Forschungszentrum Jülich GmbH, Jülich, Germany \\ *now at: Earth System Research Laboratory, NOAA, Boulder, CO, USA and Cooperative Institute for Research in the \\ Environmental Sciences, University of Colorado, Boulder, CO, USA
}

Received: 17 November 2008 - Published in Atmos. Meas. Tech. Discuss.: 2 December 2008

Revised: 27 February 2009 - Accepted: 2 March 2009 - Published: 9 March 2009

\begin{abstract}
Measurements of hydroperoxy radical $\left(\mathrm{HO}_{2}\right)$ and organic peroxy radical $\left(\mathrm{RO}_{2}\right)$ concentrations were performed by two different techniques in the atmospheric simulation chamber SAPHIR in Jülich, Germany. The first technique was the well-established Matrix Isolation Electron Spin Resonance (MIESR), which provides absolute measurements with a time resolution of $30 \mathrm{~min}$ and high accuracy $(10 \%$, $2 \sigma$ ). The other technique, ROxLIF, has been newly developed. It is based on the selective chemical conversion of $\mathrm{RO}_{\mathrm{x}}$ radicals $\left(\mathrm{HO}_{2}\right.$ and $\left.\mathrm{RO}_{2}\right)$ to $\mathrm{OH}$, which is detected with high sensitivity by laser-induced fluorescence (LIF). ROxLIF is calibrated by quantitative photolysis of water vapor at $185 \mathrm{~nm}$ and provides ambient measurements at a temporal resolution of $1 \mathrm{~min}$ and accuracy of $20 \%(2 \sigma)$. The measurements of $\mathrm{HO}_{2}$ and $\mathrm{RO}_{2}$ obtained by the two techniques were compared for two types of atmospheric simulation experiments. In one experiment, $\mathrm{HO}_{2}$ and $\mathrm{CH}_{3} \mathrm{O}_{2}$ radicals were produced by photooxidation of methane in air at tropospheric conditions. In the second experiment, $\mathrm{HO}_{2}$ and $\mathrm{C}_{2} \mathrm{H}_{5} \mathrm{O}_{2}$ were produced by ozonolysis of 1-butene in air at dark conditions. The radical concentrations were within the range of 16 to 100 pptv for $\mathrm{HO}_{2}$ and 12 to 45 pptv for $\mathrm{RO}_{2}$. Good agreement was found in the comparison of the ROxLIF and MIESR measurements within their combined experimental uncertainties. Linear regressions to the combined data set yield slopes of $1.02 \pm 0.13(1 \sigma)$ for $\mathrm{RO}_{2}$ and $0.98 \pm 0.08(1 \sigma)$ for $\mathrm{HO}_{2}$ without significant offsets. The results confirm the calibration of the ROxLIF instrument and demonstrate that it can be applied with good accuracy for measurements of atmospheric peroxy radical concentrations.
\end{abstract}

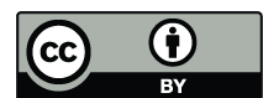

Correspondence to: A. Hofzumahaus (a.hofzumahaus@fz-juelich.de)

\section{Introduction}

Peroxy radicals play an important role in the photochemistry of the troposphere (e.g., Finlayson-Pitts and Pitts, Jr., 2000). The major source of $\mathrm{HO}_{2}$ and $\mathrm{RO}_{2}(\mathrm{R}=$ alkyl group $)$ at daytime is the reaction of photochemically formed $\mathrm{OH}$ radicals with carbon monoxide and hydrocarbons $(\mathrm{RH})$, respectively:

$$
\begin{aligned}
\mathrm{CO}+\mathrm{OH} & \rightarrow \mathrm{H}+\mathrm{CO}_{2} \\
\mathrm{H}+\mathrm{O}_{2}+\mathrm{M} & \rightarrow \mathrm{HO}_{2}+\mathrm{M} \\
\mathrm{RH}+\mathrm{OH} & \rightarrow \mathrm{R}+\mathrm{H}_{2} \mathrm{O} \\
\mathrm{R}+\mathrm{O}_{2}+\mathrm{M} & \rightarrow \mathrm{RO}_{2}+\mathrm{M}
\end{aligned}
$$

Another source of peroxy radicals is the photolysis of organic carbonyl compounds, for example, of acetaldehyde:

$$
\begin{aligned}
\mathrm{CH}_{3} \mathrm{CHO}+h v & \rightarrow \mathrm{CH}_{3}+\mathrm{HCO} \\
\mathrm{CH}_{3}+\mathrm{O}_{2}+\mathrm{M} & \rightarrow \mathrm{CH}_{3} \mathrm{O}_{2}+\mathrm{M} \\
\mathrm{HCO}+\mathrm{O}_{2} & \rightarrow \mathrm{HO}_{2}+\mathrm{CO}
\end{aligned}
$$

At night many atmospheric hydrocarbons can be oxidized by photolabile nitrate radicals $\left(\mathrm{NO}_{3}\right)$, leading to alkyl radicals and subsequently $\mathrm{RO}_{2}$ (Atkinson and Arey, 2003). Peroxy radicals are also formed in the oxidation of olefins by their reaction with ozone, which can be another significant nighttime source of $\mathrm{RO}_{2}$ and $\mathrm{HO}_{2}$ (e.g., Geyer et al., 2003; Kanaya et al., 2007).

One reason for the importance of peroxy radicals is their ability to produce tropospheric ozone. In an $\mathrm{NO}_{\mathrm{x}}(=$ $\mathrm{NO}+\mathrm{NO}_{2}$ ) rich environment, ozone is mainly destroyed and produced by photochemical cycling of $\mathrm{NO}$ and $\mathrm{NO}_{2}$ without a net change of $\mathrm{O}_{3}$ once steady state is achieved.

$$
\mathrm{NO}+\mathrm{O}_{3} \rightarrow \mathrm{NO}_{2}+\mathrm{O}_{2}
$$

Published by Copernicus Publications on behalf of the European Geosciences Union. 


$$
\begin{aligned}
\mathrm{NO}_{2}+h v & \rightarrow \mathrm{NO}+\mathrm{O}\left({ }^{3} \mathrm{P}\right) \\
\mathrm{O}\left({ }^{3} \mathrm{P}\right)+\mathrm{O}_{2}+\mathrm{M} & \rightarrow \mathrm{O}_{3}+\mathrm{M}
\end{aligned}
$$

However, if NO is oxidized by peroxy radicals, the subsequent $\mathrm{NO}_{2}$ photolysis (R9) results in a net production of tropospheric ozone:

$$
\begin{aligned}
\mathrm{RO}_{2}+\mathrm{NO} & \rightarrow \mathrm{NO}_{2}+\mathrm{RO} \\
\mathrm{RO}+\mathrm{O}_{2} & \rightarrow \mathrm{R}^{\prime} \mathrm{O}+\mathrm{HO}_{2} \\
\mathrm{HO}_{2}+\mathrm{NO} & \rightarrow \mathrm{NO}_{2}+\mathrm{OH} .
\end{aligned}
$$

Furthermore, the peroxy radical Reactions (R11)-(R13) constitute an important source of $\mathrm{OH}$ in the atmosphere. For these reasons, peroxy radical concentration measurements are essential for quantifying (1) photochemical ozone production rates, and (2) radical budgets of $\mathrm{OH}, \mathrm{HO}_{2}$ and $\mathrm{RO}_{2}$ in field studies.

Atmospheric measurements of peroxy radicals are a challenging task. Owing to their high reactivity, their maximum mixing ratios are small in the troposphere, on the order of 10 pptv during daytime (e.g., Monks, 2005). Thus, measurement instruments must have a high detection sensitivity. Reliable measurements are further complicated by the fact that the short-lived radicals can be lost by surface reactions in inlet systems of instruments. Lastly, calibrations of the instruments are difficult, because no permanently stable calibration mixtures exist for atmospheric peroxy radicals. If required, quantitative amounts of radicals must be prepared in specially designed flow reactors at the time of calibration.

Various techniques have been reported for the measurement of $\mathrm{RO}_{2}$ and $\mathrm{HO}_{2}$ : (1) matrix isolation and electron spin resonance spectroscopy, MIESR (Mihelcic et al., 1985, 1990), (2) peroxy radical chemical amplification, PERCA (Cantrell et al., 1984; Hastie et al., 1991; Burkert et al., 2001; Green et al., 2006) and (3) chemical ionization mass spectrometry, ROxMas (Reiner et al., 1997) and PerCIMS (Edwards et al., 2003). These techniques differ from each other with respect to the chemical speciation of the measured radicals. MIESR is most versatile, because it can distinguish between $\mathrm{NO}, \mathrm{NO}_{2}, \mathrm{HO}_{2}, \mathrm{CH}_{3} \mathrm{C}(\mathrm{O}) \mathrm{O}_{2}$ and $\mathrm{RO}_{2}$. The latter represents the sum of alkyl peroxy radicals, $\mathrm{RO}_{2}=\sum_{i} \mathrm{RO}_{2}{ }^{(i)}$, where $i$ denotes different organic peroxy radical species. PERCAs measure $\mathrm{RO}_{\mathrm{x}}\left(=\mathrm{RO}_{2}+\mathrm{RO}+\mathrm{HO}_{2}+\mathrm{OH}\right)$, which is a good proxy for $\mathrm{RO}_{2}+\mathrm{HO}_{2}$, while $\mathrm{OH}$ and $\mathrm{RO}$ make a negligible contribution to $\mathrm{RO}_{\mathrm{x}}$ at atmospheric conditions. The CIMS based techniques measure $\mathrm{RO}_{\mathrm{x}}$ and distinguish the contributions of $\mathrm{RO}_{2}$ and $\mathrm{HO}_{2}$ by chemical modulation.

Another class of instruments applies laser-induced fluorescence (LIF) for measurement of $\mathrm{OH}$ and $\mathrm{HO}_{2}$ (Hard et al., 1984; Hofzumahaus and Holland, 1993; Stevens et al., 1994; Brune et al., 1995; Kanaya et al., 2001; Creasey et al., 2003; Dusanter et al., 2008; Butler et al., 2008). These instruments sample ambient air by expansion into a low pressure volume, where $\mathrm{OH}$ is detected spectroscopically by laser excited fluorescence at $308 \mathrm{~nm}$. This concept is also known as fluorescence assay with gas expansion, FAGE (Hard et al., 1984).
The detection of $\mathrm{HO}_{2}$ in a FAGE instrument involves chemical conversion of $\mathrm{HO}_{2}$ to $\mathrm{OH}$ by reaction with $\mathrm{NO}$, with subsequent LIF detection of the $\mathrm{OH}$ product molecules.

Recently, we have further developed our LIF technique at Forschungszentrum Jülich to enable separate measurements of $\mathrm{OH}, \mathrm{HO}_{2}$ and $\mathrm{RO}_{2}$ concentrations with one instrument (Fuchs et al., 2008). The setup involves one measurement channel for the specific detection of $\mathrm{OH}$, while a second measurement channel (ROxLIF) is used for detection of $\mathrm{RO}_{\mathrm{x}}$. The ROxLIF concept involves a two-stage chemical conversion of $\mathrm{RO}_{\mathrm{x}}$ into $\mathrm{OH}$, which is then detected by laser induced fluorescence. Modulation of the chemical conversion conditions allows the distinction between $\mathrm{HO}_{2}$ and $\mathrm{RO}_{2}$.

In this study, we have tested the performance and calibration of the new ROxLIF instrument by a measurement comparison against the MIESR technique. The latter was chosen as a reference, because MIESR can distinguish between $\mathrm{HO}_{2}$ and $\mathrm{RO}_{2}$ radicals, and yields absolute measurements with high accuracy (Mihelcic et al., 1985, 1990). The intercomparison was performed in the atmospheric simulation chamber SAPHIR (Simulation of Atmospheric PHotochemistry In a large Reaction chamber) in Jülich. It provides a large volume of homogeneously mixed air, to which trace gases can be added at tropospheric concentration levels. For instrumental comparisons, it ensures that the instruments sample air of the same composition and at natural conditions, as was demonstrated for $\mathrm{OH}$ (Schlosser et al., 2007) and oxygenated volatile organic compounds (Apel et al., 2008). A further advantage of the use of a chamber is that experiments can be carried out at controlled conditions, allowing, for example, to keep radical concentrations constant at different levels. In this paper, we report the results of the measurement comparison between ROxLIF and MIESR for two sets of simulation experiments: (1) photochemical oxidation of methane by $\mathrm{OH}$ as an example for daytime production of peroxy radicals, and (2) ozonolysis of 1-butene as an example for a nighttime source of peroxy radicals.

\section{Instrumental description}

\subsection{SAPHIR chamber and instrumentation}

SAPHIR is designed to investigate photochemical processes under ambient conditions with atmospheric concentrations of traces gases. Detailed descriptions, focussing on particular experiments in SAPHIR, were given in the papers by Bohn and Zilken (2005), Rohrer et al. (2005), and Wegener et al. (2007). Therefore, only a short description is given here.

The reaction chamber consists of a double-walled FEP film of $125 \mu \mathrm{m}$ to $250 \mu \mathrm{m}$ thickness arranged in a cylindrical shape (inner diameter $5 \mathrm{~m}$, length $20 \mathrm{~m}$, volume $270 \mathrm{~m}^{3}$ ). The film is chemically inert and it has an acceptable light transmission over the whole wavelength range of ultraviolet and visible sunlight that reaches the ground. The chamber 
can be exposed to sunlight or can be kept dark by employing a fast shutter system.

The space between both films of the chamber wall is flushed permanently with clean nitrogen to avoid uncontrolled diffusion of ambient trace gases into the inner volume of the chamber. SAPHIR is operated at ambient temperature and at a pressure which is slightly $(30-50 \mathrm{hPa})$ above ambient pressure. Before experiments take place, the gas inside the chamber is exchanged by clean synthetic air at a maximum flow rate of $500 \mathrm{~m}^{3} / \mathrm{h}$ until the concentrations of trace gases are below the detection limits of the attached measurement instruments. Trace gases can be injected into the chamber and are mixed to the chamber air by a fan within a few minutes. Air which is consumed by measurement devices or is lost by chamber leakages is constantly replaced with clean synthetic air, in this study at a rate of approximately $7 \mathrm{~m}^{3} / \mathrm{h}$.

If the reaction chamber is exposed to sunlight, two chemical compounds, nitrous acid (HONO) and formaldehyde (HCHO) are produced photolytically on the surface of the Teflon film (Rohrer et al., 2005; Karl et al., 2004). Although the detailed mechanism of these processes is not known, the source strengths of $\mathrm{HONO}$ and $\mathrm{HCHO}$ emissions into the chamber are well characterized by previous experiments. The quantification of these processes is important, because the following photolysis of $\mathrm{HONO}$ and $\mathrm{HCHO}$ in the gas phase constitutes a source of $\mathrm{OH}$ and $\mathrm{HO}_{2}$, respectively.

In this work, parameters like temperature, pressure, relative humidity and experimental flows in the chamber were routinely monitored during all experiments. The solar actinic flux was measured by a spectroradiometer and used for the calculation of photolysis frequencies (Bohn and Zilken, 2005). $\mathrm{NO}, \mathrm{NO}_{2}$, and $\mathrm{O}_{3}$ concentrations were measured by chemiluminescence detectors (Eco Physics, CLD 780TR). A gas chromatograph (Chrompack, Chrompack VOCAir) measured the concentrations of non-methane hydrocarbons. In one set of experiments, 1-butene was ozonolyzed for peroxy radical generation in the chamber. Here, 1-butene was measured by the GC instrument and simultaneously monitored by the NO chemiluminescence detector in the so called "zero mode", which serves to quantify and subtract interference signals from the reaction of alkenes with ozone. The interference signal of the chemiluminescence detector was calibrated against the GC measurements and provided a quasicontinuous measurement of 1-butene, while the time resolution of the GC was about $20 \mathrm{~min}$.

\subsection{ROxLIF technique}

The LIF instrument applies one measurement channel for $\mathrm{OH}$ (Holland et al., 2003) and a second channel (ROxLIF) for the measurement of $\mathrm{RO}_{2}$ and $\mathrm{HO}_{2}$. ROxLIF is a newly developed technique, which has been described in detail elsewhere (Fuchs et al., 2008). It applies chemical conversion in combination with LIF for radical detection and can be operated in two chemical modes (ROx and HOx mode).
In brief, ambient air is sampled through an orifice $(1 \mathrm{~mm}$ diameter) into a differentially pumped flow reactor, which is kept at a reduced pressure of $25 \mathrm{hPa}$. In the ROx mode, $\mathrm{NO}$ and $\mathrm{CO}$ are added as reagents to the sampled air, in order to convert atmospheric $\mathrm{RO}_{\mathrm{x}}$ to $\mathrm{HO}_{2}$. $\mathrm{NO}(0.7 \mathrm{ppmv})$ is responsible for the successive conversion of atmospheric $\mathrm{RO}_{2}$ to $\mathrm{HO}_{2}$ and $\mathrm{HO}_{2}$ to $\mathrm{OH}$ (Reactions R11-R13). In contrast to previous detection of $\mathrm{HO}_{2}$ by LIF, where $\mathrm{RO}_{2}$ conversion was limited by the short reaction time and dilution of oxygen required in Reaction (R12), the reaction time of $0.6 \mathrm{~s}$ is long enough and the oxygen concentration high enough for quantitative conversion. The large amount of $\mathrm{CO}(0.17 \%)$ ensures that all $\mathrm{HO}_{\mathrm{x}}\left(=\mathrm{HO}_{2}+\mathrm{OH}\right)$, from ambient air and from $\mathrm{RO}_{2}$ conversion, becomes $\mathrm{HO}_{2}$ (Reactions $\mathrm{R} 1$ and $\mathrm{R} 2$ ). This has the advantage that potential $\mathrm{HO}_{\mathrm{x}}$ loss by reactions of the highly reactive $\mathrm{OH}$ becomes negligible in the reactor. In the $\mathrm{HOx}$ mode, the NO reagent is turned off and only $\mathrm{CO}$ is added. At this condition, only atmospheric $\mathrm{HO}_{\mathrm{x}}$ is converted to $\mathrm{HO}_{2}$. The alternating measurement in the $\mathrm{HO}_{\mathrm{x}}$ and $\mathrm{RO}_{\mathrm{x}}$ mode allows to distinguish between $\mathrm{HO}_{\mathrm{x}}$ and $\mathrm{RO}_{2}$ radical concentrations.

At the exit of the reactor, the central gas flow is transferred through a nozzle into a detection chamber at even lower pressure ( $3.5 \mathrm{hPa})$. Here, additional $\mathrm{NO}$ is injected into the sampled gas, causing nearly complete chemical conversion of $\mathrm{HO}_{2}$ to $\mathrm{OH}$ (Reaction R13), which is detected by LIF. A pulsed narrow-bandwidth UV laser $(308 \mathrm{~nm})$ is used to excite the $\mathrm{OH}$ radicals at the rovibronic line $\mathrm{Q}_{1}(3)$ of the $\mathrm{A}^{2} \Sigma^{+} v^{\prime}=0-\mathrm{X}^{2} \Pi v^{\prime \prime}=0$ transition, and the resulting resonance fluorescence is measured by gated photon counting. The laser is tuned periodically on and off resonance to distinguish the $\mathrm{OH}$ fluorescence signal from non-resonant background signals.

The calibration of the ROxLIF measurements is based on the quantitative photolysis of water vapor in air at a wavelength of $185 \mathrm{~nm}$. The photolysis produces equal concentrations of $\mathrm{OH}$ and $\mathrm{HO}_{2}$ and is widely applied for calibration of $\mathrm{HO}_{\mathrm{x}}$ instruments (Aschmutat et al., 1994; Schultz et al., 1995; Heard and Pilling, 2003). In the present work, a modified concept is used for peroxy radicals (Schultz et al., 1995; Hanke et al., 2002; Qi et al., 2006; Fuchs et al., 2008). The photolytically generated $\mathrm{OH}$ is completely converted to $\mathrm{HO}_{2}$ by adding excess $\mathrm{CO}$ (Reactions R1 and R2) in order to determine the $\mathrm{HO}_{2}$ sensitivity. To calibrate the ROxLIF instrument for $\mathrm{RO}_{2}$, a corresponding hydrocarbon $(\mathrm{RH})$ is added to the calibration gas, resulting in the complete conversion of $\mathrm{OH}$ to $\mathrm{RO}_{2}$ (Reactions $\mathrm{R} 3$ and $\mathrm{R} 4$ ). In the present work only methane was used for $\mathrm{RO}_{2}$ calibrations. This simplified procedure is justified as the ROxLIF detection sensitivity is essentially the same for the two radical species $\left(\mathrm{CH}_{3} \mathrm{O}_{2}\right.$ and $\mathrm{C}_{2} \mathrm{H}_{5} \mathrm{O}_{2}$ ), which were generated in the SAPHIR experiments reported below (Fuchs et al., 2008). The similar detectivity is plausible, since alkyl peroxy radicals show similar reaction rate constants towards their reaction with $\mathrm{NO}$ (Atkinson and Arey, 2003), which is the rate limiting step in 
the $\mathrm{RO}_{2}$ to $\mathrm{HO}_{2}$ conversion in the flow reactor of the instrument. The estimated accuracy of calibration is approximately $20 \%(2 \sigma)$ limiting the accuracy of ROxLIF measurements. The sensitivity of the instrument is corrected for fluorescence quenching by water vapor, but there is no chemical interference from water vapor as observed in PERCA instruments (Mihele and Hastie, 1998). If sampling highly polluted air, interferences such as thermal decomposition of atmospheric peroxy nitrates could reduce the accuracy, but such conditions were not encountered in the current experiments. The detection limits $(\mathrm{SNR}=2)$ are 0.1 pptv for both $\mathrm{HO}_{2}$ and $\mathrm{RO}_{2}$ at a time resolution of $1 \mathrm{~min}$ (Fuchs et al., 2008).

In the reported experiments, the flow reactor of the instrument extended into the SAPHIR chamber. The sampling point was $87 \mathrm{~cm}$ above the floor of the chamber. The outer surfaces of the reactor (except the inlet region) were covered with a Teflon bag in order to minimize possible radical losses on instrumental surfaces close to the inlet.

\subsection{MIESR technique}

MIESR was developed as a measurement technique for atmospheric peroxy radicals at the Forschungszentrum Jülich by Mihelcic et al. $(1985,1990)$ and is the only one of its kind. It has the capability to measure simultaneously the concentrations of $\mathrm{HO}_{2}, \mathrm{RO}_{2}, \mathrm{CH}_{3} \mathrm{C}(\mathrm{O}) \mathrm{O}_{2}, \mathrm{NO}_{3}$ and $\mathrm{NO}_{2}$ in the same sample of air.

The MIESR technique is an offline method. Ambient air is collected by gas expansion through a nozzle into a vacuum chamber. The radicals are trapped from the gas jet in a polycrystalline $\mathrm{D}_{2} \mathrm{O}$ matrix which is formed in situ on a cold finger at a temperature of $77 \mathrm{~K}$. The collection time for an air sample is $30 \mathrm{~min}$. The samples are stored and measured under vacuum at $77 \mathrm{~K}$. At this condition, the ice matrix prevents chemical interactions between reactive molecules and allows to store the sample up to several weeks without loss of radicals. Speciation and quantification of the trapped radicals are achieved in the laboratory by electron spin resonance spectroscopy. The spectra are analyzed by a nonlinear fitting procedure (Mihelcic et al., 1990). $\mathrm{HO}_{2}, \mathrm{CH}_{3} \mathrm{C}(\mathrm{O}) \mathrm{O}_{2}, \mathrm{NO}_{3}$ and $\mathrm{NO}_{2}$ can be individually measured, whereas the spectra of organic peroxy radicals overlap and provide a measure of $\mathrm{RO}_{2}$. The MIESR technique is an absolute technique and achieves a detection limit of 2 pptv for peroxy radicals at a time resolution of $30 \mathrm{~min}$ (Mihelcic et al., 2003). The main advantage of this method is that no calibration of the instrument is required, making it useful as a reference method for other atmospheric $\mathrm{RO}_{\mathrm{x}}$ measurement techniques (Platt et al., 2002). The accuracy of measurements is $5 \%$.

In the reported experiments, the MIESR sampling unit was mounted in a flange at the bottom of the SAPHIR chamber. In this setup, the upward oriented inlet nozzle of the sampling unit was about $2 \mathrm{~cm}$ above the chamber floor, which consists of a Teflon film. The horizontal distance between the MIESR sampling unit and the ROxLIF reactor was approximately
$3 \mathrm{~m}$. Turbulent mixing of the chamber air ensures that the relatively short distance between sampling point and chamber surface does not lead to gradients in the radical concentrations, which would affect the intercomparison (Schlosser et al., 2007).

\section{Results}

Two types of experiments were carried out in SAPHIR which provided atmospheric radical concentrations. The first experiment was performed at daylight and involved the photochemical oxidation of methane, while the second experiment involved ozonolysis of 1-butene at dark conditions. Raw data were evaluated independently by the operators of the two instruments without communicating results before final data were exchanged.

\subsection{Methane photooxidation experiment}

After purging the chamber with dry synthetic air overnight, water vapor was introduced into the dark chamber in the morning. High purity water was provided by a Milli-Q-water device (Millipore Corp., Milli-Q Gradient A10), vaporized and flushed into the chamber together with a high flow of synthetic air, until a water vapor mixing ratio of about $0.7 \%$ by volume (relative humidity: $50 \%$ ) was achieved. Methane (Air Liquide, purity 5.5) was introduced into the chamber, resulting in an initial large mixing ratio of approximately $0.5 \%$ by volume. Fast mixing in the chamber was achieved by a fan, which was operated for the entire duration of the experiment. After the gas addition, the shutter system of the chamber was opened at 08:00 UTC for a duration of 5.5 h. The experiment was stopped at 14:30 UTC. The ROxLIF instrument was running continuously during the whole period, while the MIESR instrument took three air samples of $30 \mathrm{~min}$ integration time, starting at 09:00, 10:00 and 11:00 UTC.

The peroxy radical measurements of the ROxLIF and MIESR instrument are shown in Fig. 1, together with the HONO photolysis frequency, $j$ (HONO), and the mixing ratio of NO. Dashed vertical lines indicate the opening and closing of the shutter system. As soon as the shutter was opened and sunlight entered the chamber, $\mathrm{HO}_{2}$ and $\mathrm{RO}_{2}$ concentrations measured by ROxLIF increased during the first minutes up to 15-20 pptv. Both, $\mathrm{HO}_{2}$ and $\mathrm{RO}_{2}$, showed similar diurnal variations and reached approximately the same peak concentrations of $40 \mathrm{pptv}$ at 12:30 UTC. The concentrations measured by ROxLIF agree very well with the simultaneous measurements by MIESR during the time of measurement overlap (9:00-11:30 UTC). Short-term fluctuations of the radical concentrations measured by ROxLIF were mainly correlated with variations of the solar UV radiation represented by $j(\mathrm{HONO})$. The $\mathrm{OH}$ radical concentration (not shown here) remained always below the detection limit $\left(<1 \times 10^{6} \mathrm{~cm}^{-3}\right)$ of the LIF instrument. After the shutter of 


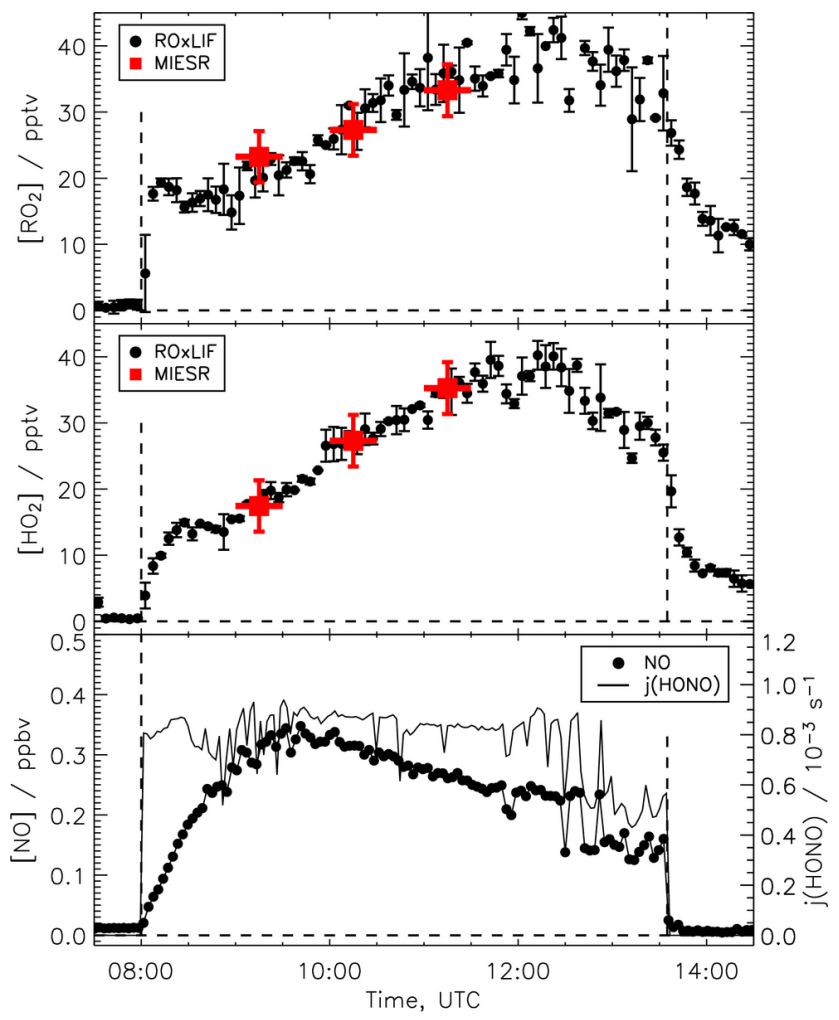

Fig. 1. Comparison of peroxy radical concentrations measured simultaneously by ROxLIF (5 min average values) and MIESR during the methane photooxidation experiment (upper panel: $\mathrm{RO}_{2}$, middle panel: $\mathrm{HO}_{2}$ ). Vertical error bars represent the $1 \sigma$ precisions of the measurements. Horizontal bars denote the $30 \mathrm{~min}$ sampling time intervals of the MIESR measurements. The bottom panel shows mixing ratios of NO measured by chemiluminescence and the HONO photolysis frequency measured by a spectroradiometer. Dashed vertical lines indicate the opening and closing of the shutter system of the chamber.

the chamber had been closed, the photolytic radical production stopped, followed by a decay of the radical concentrations. The mixing ratios of $\mathrm{NO}_{\mathrm{x}}$ and $\mathrm{O}_{3}$ (not shown here) increased continuously over the course of the experiment, starting at zero concentrations at 08:00 UTC and reached maximum values of $2.8 \mathrm{ppbv}$ and $65 \mathrm{ppbv}$ at 13:30 UTC, respectively.

\subsection{1-butene ozonolysis experiment}

The ozonolysis experiment was performed at dark conditions, keeping the shutter system of the chamber closed all the time. After purging the chamber overnight with clean synthetic air, ozone was generated by a silent discharge ozonizer and introduced into the chamber. The amount of added $\mathrm{O}_{3}$ was accurately controlled by a magnetic valve in the inlet line, which was opened and closed by an electronic timer. The ozone mixing ratio was increased in four steps

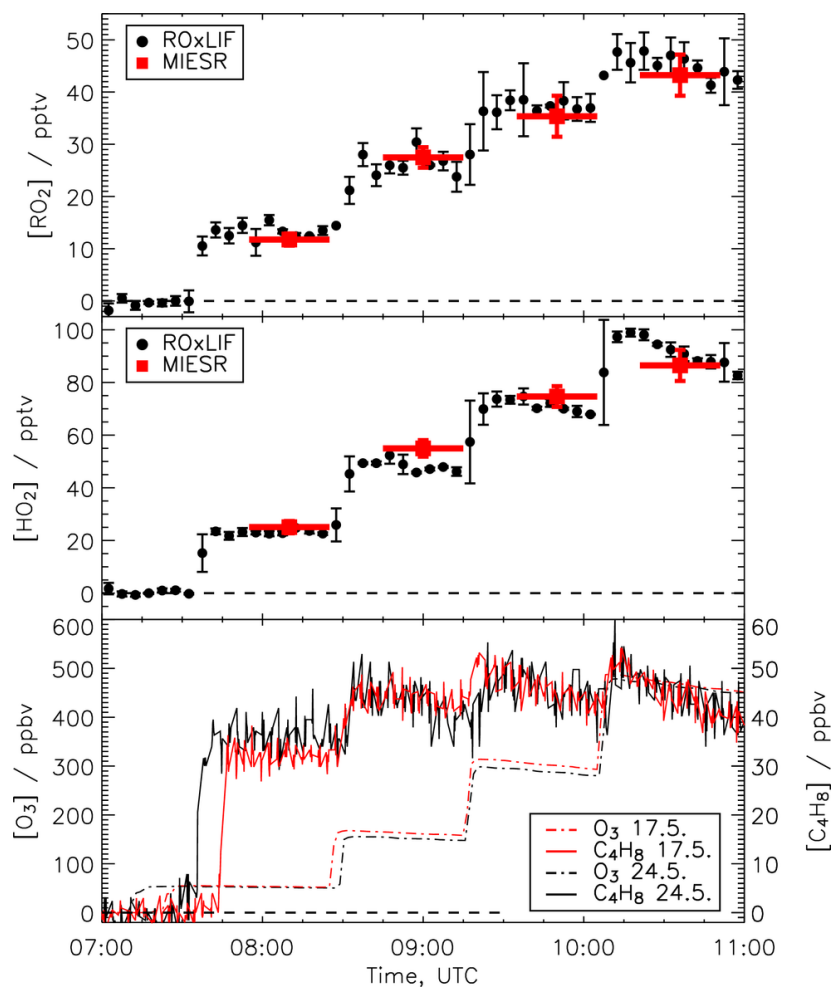

Fig. 2. Comparison of peroxy radical concentrations measured by ROxLIF (5 min average values) and MIESR during the 1-butene ozonolysis experiments on 24 May 2006 and 17 May 2006, respectively (upper panel: $\mathrm{RO}_{2}$, middle panel: $\mathrm{HO}_{2}$ ). Vertical error bars represent the $1 \sigma$ precisions of the measurements. Horizontal bars denote the 30 min sampling time intervals of the MIESR measurements. The bottom panel shows the corresponding concentrations of ozone and 1-butene during the two experimental runs.

from 50 ppbv to a maximum of nearly $500 \mathrm{ppbv}$ (Fig. 2). The water vapor mixing ratio was about $0.04 \%$ by volume all the time. In addition, $480 \mathrm{ppmv} \mathrm{CO}$ were initially introduced to the chamber, serving as a scavenger for $\mathrm{OH}$ and stabilized Criegee radicals. After the first addition of ozone, 1-butene (Linde AG, purity 3.5) was injected into the chamber, yielding an initial concentration of $36 \mathrm{ppbv}$. The slow decrease of 1-butene during the following experiment was balanced by further additions of 1-butene (each corresponding to an incremental increase of $12 \mathrm{ppbv}$ ), added at the same time when the ozone concentration was increased. The complete experiment was performed twice, once on 17 May 2006 and a second time on 24 May 2006, at nearly the same chemical conditions (see bottom panel of Fig. 2).

Nearly constant mixing ratios of $\mathrm{HO}_{2}$ and $\mathrm{RO}_{2}$ were produced in the chamber at five different concentration levels reaching from zero to a maximum of $100 \mathrm{pptv}$ of $\mathrm{HO}_{2}$ and $45 \mathrm{pptv}$ of $\mathrm{RO}_{2}$. The stepwise increase of concentrations was caused by the incremental additions of $\mathrm{O}_{3}$ and 1-butene. In the first experimental run (17 May 2006), the 
MIESR instrument collected four samples, each at a different level of peroxy radical concentrations for $30 \mathrm{~min}$. The sampling was started approximately $15 \mathrm{~min}$ after each addition of $\mathrm{O}_{3}$ and 1-butene, in order to ensure that the air in the chamber was homogeneously mixed and the chemical system was equilibrated. The ROxLIF instrument was running in parallel, but due to a technical failure of its flow reactor, measurements became flawed and had to be discarded. The ROxLIF measurements were repeated in the second experimental run on 24 May 2006, where the chemical conditions from 17 May 2006 were closely reproduced. This time the ROxLIF system worked properly, however, the MIESR sampler was no longer available, because it had been moved to the laboratory for analysis of the previously taken samples. Thus, the ROxLIF and MIESR data shown in Fig. 2 were not obtained simultaneously. However, as the chemical conditions were nearly the same, a comparison of the two data sets is possible (see discussion below). Based on this assumption, the results demonstrate a good agreement between the ROxLIF and MIESR technique for measurement of both $\mathrm{HO}_{2}$ and $\mathrm{RO}_{2}$ in the ozonolysis experiments.

\section{Discussion}

\subsection{Peroxy radical production by methane oxidation}

The chamber experiments were designed to produce $\mathrm{HO}_{2}$ and one particular $\mathrm{RO}_{2}$ species in each type of experiment. In the methane photooxidation experiment, traces of methane and water vapor were exposed to solar radiation in synthetic air at ambient temperature and pressure. It is expected that this mixture produces $\mathrm{CH}_{3} \mathrm{O}_{2}$ and $\mathrm{HO}_{2}$ as the only peroxy radicals in the SAPHIR chamber at the given conditions. As soon as sunlight enters the chamber, i.e. when the shutter system is opened, production of $\mathrm{OH}$ is started by photolysis of HONO, which is formed heterogeneously at the sunlit chamber walls (see Sect. 2.1). The HONO photolysis is also a source for $\mathrm{NO}$ in the gas phase, which starts to built up when the chamber is illuminated. The high concentration of methane $(0.5 \%)$ ensures that $\mathrm{OH}$ reacts quickly and exclusively to $\mathrm{CH}_{3} \mathrm{O}_{2}$, which is further converted by the available $\mathrm{NO}$ to $\mathrm{HO}_{2}$. Recycled $\mathrm{OH}$ from the reaction of $\mathrm{HO}_{2}$ and $\mathrm{NO}$ is immediately consumed by methane again. This sequence of radical reactions explains why the observed concentrations of $\mathrm{CH}_{3} \mathrm{O}_{2}$ and $\mathrm{HO}_{2}$ exhibit a similar time dependence and show similar concentrations during the course of the experiment. $\mathrm{HO}_{2}$ is formed predominantly from $\mathrm{CH}_{3} \mathrm{O}_{2}$, and both, $\mathrm{HO}_{2}$ and $\mathrm{CH}_{3} \mathrm{O}_{2}$, are depleted mainly by reaction with $\mathrm{NO}$, which has nearly the same rate constant for both radical species (Sander et al., 2006). Thus, approximately equal steady-state concentrations are expected for both radical species.

The high methane concentration in the chamber led to a reduction in the ROxLIF sensitivity, because $\mathrm{OH}$ radicals pro- duced in the conversion reactor partly regenerated $\mathrm{CH}_{3} \mathrm{O}_{2}$ radicals. Model calculations of the reaction kinetics in the reactor show a reduction of the sensitivity of $4 \%$ for $\mathrm{RO}_{2}$ and $9 \%$ for $\mathrm{HO}_{2}$ for a methane mixing ratio of $0.5 \%$. Since methane was not measured during this experiment and the initial mixing ratio was only estimated from its addition before the experiment started, this effect was not taken into account in the data evaluation and adds to the uncertainty in the ROxLIF measurements.

\subsection{Peroxy radical production by 1-butene ozonolysis}

In the dark ozonolysis experiments, ozone and 1-butene were mixed in $1 \mathrm{~atm}$ of dry synthetic air, which was additionally loaded with $\mathrm{CO}$ as an $\mathrm{OH}$ scavenger. The ozonolysis involves a complex system of chemical reactions, which yield various products (Grosjean et al., 1996; Grosjean and Grosjean, 1997; Olzman et al., 1997; Hasson et al., 2001; Wegener et al., 2007). In the first step, ozone is cycloadded to the alkene and forms an ozonide, which rapidly decomposes to either formaldehyde or propanal and a corresponding excited Criegee intermediate, $\mathrm{C}_{2} \mathrm{H}_{5} \mathrm{CHOO}^{*}$ or $\mathrm{HCHOO}^{*}$, respectively. The two types of Criegee intermediates undergo fast decomposition reactions, yielding $\mathrm{OH}, \mathrm{HO}_{2}$ and $\mathrm{C}_{2} \mathrm{H}_{5} \mathrm{O}_{2}$ radicals and stable byproducts (e.g., $\mathrm{C}_{2} \mathrm{H}_{6}, \mathrm{CO}, \mathrm{CO}_{2}$ ) or can be stabilized by collisions. The stabilized Criegee intermediates react with the large excess of $\mathrm{CO}$ initially injected into the chamber to corresponding aldehydes and $\mathrm{CO}_{2}$ (Atkinson, 1997; Hatakeyama et al., 1994). The large amount of CO also converts $\mathrm{OH}$ completely to $\mathrm{HO}_{2}$ and prevents possible reactions of $\mathrm{OH}$ with 1-butene and its ozonolysis products. Thus, the chemical system is expected to produce $\mathrm{C}_{2} \mathrm{H}_{5} \mathrm{O}_{2}$ and $\mathrm{HO}_{2}$ as the only peroxy radicals in the chamber.

Interferences of the ROxLIF measurement from Criegee intermediates are not expected in these experiments. The excited Criegee radicals from the ozonolysis reactions are short-lived intermediates in the formation process of the peroxy radicals, and as their chemical lifetime is very much shorter, their concentrations are negligible compared to those of the peroxy radicals (Jenkin et al., 1997). Stabilized Criegee radicals also do not play a role, because they are efficiently scavenged and converted to non-radical products by the high concentration of $\mathrm{CO}$ in the SAPHIR chamber and in the ROxLIF converter (Atkinson, 1997; Hatakeyama et al., 1994).

Peroxy radical concentrations are controlled by the concentrations of the precursors ozone and 1-butene, which slowly react with each other on a time scale of several hours, at a rate constant of $\sim 1 \times 10^{-17} \mathrm{~cm}^{-3} \mathrm{~s}^{-1}$ (Atkinson and Arey, 2003). While the radical production is rate limited by this reaction, the radical destruction in the absence of NO is determined by the much faster recombination reactions of the peroxy radicals $\left(\mathrm{HO}_{2}+\mathrm{HO}_{2}, \mathrm{HO}_{2}+\mathrm{RO}_{2}\right.$, and $\mathrm{RO}_{2}+\mathrm{RO}_{2}$ ). The overall reaction kinetics has two interesting consequences. First, as 1-butene and ozone are depleted 
slowly, the resulting steady-state concentrations of the peroxy radicals stay nearly constant over the $1 \mathrm{~h}$ observation periods applied in the ozonolysis experiments (Fig. 2). Second, the radical concentrations can be easily reproduced by adjustment of the ozone and alkene concentrations.

The chemical behavior of the reaction system and the fact that the two ozonolysis experiments (17 and 24 May 2006) were performed in clean synthetic air and at dark conditions, avoiding variable photolytical radical production, is the basis for the reproducibility of the experiments. In fact, the amount of reagents for radical production and the timing of their incremental additions were almost the same during both runs (see Fig. 2, bottom panel). The maximum difference in the measured ozone concentrations was 3\% during the time intervals, where MIESR and ROxLIF measurements are compared. The corresponding concentrations of 1-butene differed by $12 \%$ after the first addition, but were equal for the following concentration levels of the experiments within the precision of the 1-butene measurement. For these reasons, it can be assumed that the time series of the relevant peroxy radical concentrations were essentially the same during both runs. Based on this assumption, it is justified to compare the measurements by ROxLIF and MIESR for both $\mathrm{HO}_{2}$ and $\mathrm{RO}_{2}$ in the ozonolysis experiments.

\subsection{Measurement intercomparison}

For quantitative analysis, the ROxLIF measurements are averaged over the sampling time period of the MIESR instrument and are compared in scatter plots versus the MIESR measurements in Fig. 3.

The $\mathrm{HO}_{2}$ data in the right panel show a linear relationship with little scatter and follow closely a 1:1 line. A linear fit, which takes into account the statistical errors of both instruments ("FitExy" procedure in Press et al. (1992)), yields a slope of $0.98 \pm 0.08$, an intercept of $(-1.2 \pm 3.8)$ pptv and a linear correlation coefficient $R^{2}$ of 0.98 . The scatter of the individual data points around the regression line can be explained by their statistical precision. This is confirmed by the goodness-of-fit probability $q$ of 0.65 . This fitting parameter indicates a linear relationship of the data within their statistical errors, if $q>0.1$ (Press et al., 1992). The intercept of the regression line is not significant and can be explained by its statistical error.

The scatter plot for $\mathrm{RO}_{2}$ in the left panel of Fig. 3 shows a similar good correlation as for $\mathrm{HO}_{2}$. The data follow a linear relationship of nearly unity slope and exhibit a correlation coefficient $R^{2}=0.97$. No significant difference can be seen between the data points from the methane photooxidation and 1-butene ozonolysis experiments. This confirms that the ROxLIF instrument, which was calibrated for $\mathrm{CH}_{3} \mathrm{O}_{2}$ (see Sect. 2.2), is equally sensitive to $\mathrm{CH}_{3} \mathrm{O}_{2}$ and $\mathrm{C}_{2} \mathrm{H}_{5} \mathrm{O}_{2}$. The regression line for the combined $\mathrm{RO}_{2}$ data exhibits a slope of $1.02 \pm 0.13$, an intercept of $(0.5 \pm 4.0)$ pptv and a parameter $q$ of 0.93. As for $\mathrm{HO}_{2}$, no significant offset is observed.

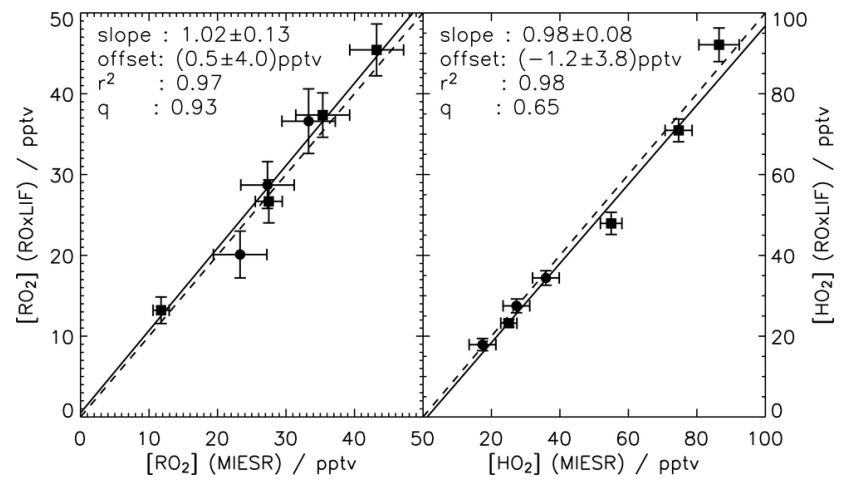

Fig. 3. Correlation of peroxy radical data measured by ROxLIF and MIESR (left panel: $\mathrm{RO}_{2}$, right panel: $\mathrm{HO}_{2}$ ). Square symbols represent data from the ozonolysis experiments and circles from the methane photooxidation experiment. For these presentations the ROxLIF data were averaged over the sampling time interval of MIESR. Error bars are $1 \sigma$ standard deviations of average ROxLIF values or $1 \sigma$ measurement errors of MIESR. The black lines represent linear fits that take into account the errors of both measurement instruments (Press et al., 1992). The corresponding fitting parameters (slope and offset, correlation coefficient $\mathrm{r}^{2}$ and $\mathrm{q}$ as the probability for a linear fit) are given with their $1 \sigma$ errors in the legends. The dashed lines represent 1:1 lines.

The slopes of the regression lines for $\mathrm{HO}_{2}$ and $\mathrm{RO}_{2}$ indicate very good agreement of the two measurement techniques within their combined uncertainties. The uncertainties are determined by the calibration accuracy of $20 \%(2 \sigma)$ of the ROxLIF instrument (Fuchs et al., 2008) and the 10\% $(2 \sigma)$ measurement error of MIESR (Mihelcic et al., 2003). As a result, the measurement comparison confirms the calibration of the ROxLIF technique, here demonstrated for $\mathrm{HO}_{2}, \mathrm{CH}_{3} \mathrm{O}_{2}$ and $\mathrm{C}_{2} \mathrm{H}_{5} \mathrm{O}_{2}$.

The present work is the first, in which two measurement instruments have been compared for speciated peroxy radicals at atmospheric conditions. Earlier studies have either compared measurements of atmospheric $\mathrm{HO}_{2}$ or total peroxy radicals. $\mathrm{HO}_{2}$ measurements were first compared between LIF and MIESR during the BERLIOZ field campaign (Platt et al., 2002; Mihelcic et al., 2003). Good agreement was observed as indicated by a slope of $1.03 \pm 0.08$ and a correlation coefficient $R^{2}$ of 0.88 (Platt et al., 2002). The same campaign offered also an opportunity to compare $\mathrm{RO}_{\mathrm{x}}$ measurements by a PERCA instrument and MIESR. A regression line with a slope of 1.07 and a correlation coefficient $R^{2}=0.91$ demonstrated good agreement for these measurements (Platt et al., 2002). In another more recent study, $\mathrm{HO}_{2}$ measurements were compared between a PerCIMS and LIF instrument in two phases: 1 . by mutual exchange of calibration sources, 2. by ambient air measurements (Ren et al., 2003). In the calibration intercomparison, very good agreement was found within 2\% for PerCIMS sampling from the LIF calibration 
source and within $4 \%$ for LIF sampling from the PerCIMS calibration source. Good agreement was also obtained in a side-by-side intercomparison of the ambient $\mathrm{HO}_{2}$ measurements. Here, the regression line yielded a slope of 0.96 and a correlation coefficient $R^{2}=0.85$. It is noteworthy that the calibrations of both techniques applied water vapor photolysis at $185 \mathrm{~nm}$, which is also the basis for the ROxLIF calibration in the present work. MIESR, however, which was used as a reference in the present and previous intercomparisons, is an independent technique requiring no calibration. The result of the present intercomparison is therefore important support for the general concept of water photolysis as a tool for peroxy radical calibrations.

\section{Conclusions}

An intercomparison of speciated measurements of concentrations of $\mathrm{HO}_{2}$ and two alkyl peroxy radicals, $\mathrm{CH}_{3} \mathrm{O}_{2}$ and $\mathrm{C}_{2} \mathrm{H}_{5} \mathrm{O}_{2}$, has been performed successfully between the fundamentally different ROxLIF and MIESR techniques. Very good agreement of the two instruments was observed during two types of simulation experiments carried out in the atmosphere simulation chamber SAPHIR. This facility ensured that both instruments sampled well mixed air of the same chemical composition and allowed the design of experiments, in which only one specific type of $\mathrm{RO}_{2}$ radical is produced together with $\mathrm{HO}_{2}$. In the photooxidation of methane, concentrations of $\mathrm{CH}_{3} \mathrm{O}_{2}$ and $\mathrm{HO}_{2}$ were prepared, which were dependent on the strength of the natural sunlight. In the 1-butene ozonolysis experiments, nearly constant radical concentrations of $\mathrm{C}_{2} \mathrm{H}_{5} \mathrm{O}_{2}$ and $\mathrm{HO}_{2}$ were generated, which were entirely controlled by the chosen concentrations of the reactants ozone and 1-butene.

The good agreement of the measurements by the newly developed ROxLIF and the well established MIESR technique strengthens the confidence in the measurement and calibration of the new instrument. The ROxLIF technique has advantages over the MIESR technique by offering a higher time resolution and a better detection sensitivity. The SAPHIR chamber offers the potential to serve as a reference standard for peroxy radical concentrations. As has been demonstrated in this work, the ozonolysis of 1-butene allows the controlled production of $\mathrm{HO}_{2}$ and $\mathrm{C}_{2} \mathrm{H}_{5} \mathrm{O}_{2}$ at dark conditions. The capability to create constant radical concentrations is of advantage for intercomparison of instruments, which need a relative long sampling time. The peroxy radical concentrations obtained from the 1-butene ozonolysis have been quantified in this work and can be reproduced at any time in the chamber for future quality assurance tests.

Acknowledgements. We thank B. Bohn for providing the measured data of the HONO photolysis frequencies.

Edited by: D. Heard

\section{References}

Apel, E. C., Brauers, T., Koppmann, R., Bandowe, B., Boßmeyer, J., Holzke, C., Tillmann, R., Wahner, A., Wegener, R., Brunner, A., Jocher, M., Ruuskanen, T., Spirig, C., Steigner, D., Steinbrecher, R., Gomez Alvarez, E., Müller, K., Burrows, J. P., Schade, G., Solomon, S. J., Ladstätter-Weißenmayer, A., Simmonds, P., Young, D., Hopkins, J. R., Lewis, A. C., Legreid, G., Reimann, S., Hansel, A., Wisthaler, A., Blake, R. S., Ellis, A. M., Monks, P. S., and Wyche, K. P.: Intercomparison of oxygenated volatile organic compound measurements at the SAPHIR atmosphere simulation chamber, J. Geophys. Res., 113, D20307, doi:10.1029/2008JD009865, 2008.

Aschmutat, U., Heßling, M., Holland, F., and Hofzumahaus, A.: A tunable source of hydroxyl $(\mathrm{OH})$ and hydroperoxy $\left(\mathrm{HO}_{2}\right)$ radicals: In the range between $10^{6}$ and $10^{9} \mathrm{~cm}^{-3}$, in: Physicochemical behaviour of atmospheric pollutants, edtited by G. Angeletti and G. Restelli, European Commission, Brussels, 811816, 1994.

Atkinson, R.: Gase-phase tropospheric chemistry of volatile organic compounds: 1. alkanes and alkenes, J. Phys. Chem. Ref. Data, 26, 217-219, 1997.

Atkinson, R. and Arey, J.: Atmospheric Degradation of Volatile Organic Compounds, Chem. Rev., 103, 4605-4638, 2003.

Bohn, B. and Zilken, H.: Model-aided radiometric determination of photolysis frequencies in a sunlit atmosphere simulation chamber, Atmos. Chem. Phys., 5, 191-206, 2005,

http://www.atmos-chem-phys.net/5/191/2005/.

Brune, W. H., Stevens, P. S., and Mather, J. H.: Measuring OH and $\mathrm{HO}_{2}$ radicals in the troposphere by laser-induced fluorescence at low pressure, J. Atmos. Sci., 52, 3328-3336, 1995.

Burkert, J., Andrés Hernández, M.-D., Stöbener, D., Weissenmayer, M., and Kraus, A.: Peroxy radical and related trace gas measurements in the boundary layer above the Atlantic Ocean, J. Geophys. Res., 106, 5457-5477, 2001.

Butler, T. M., Taraborrelli, D., Brühl, C., Fischer, H., Harder, H., Martinez, M., Williams, J., Lawrence, M. G., and Lelieveld, J.: Improved simulation of isoprene oxidation chemistry with the ECHAM5/MESSy chemistry-climate model: lessons from the GABRIEL airborne field campaign, Atmos. Chem. Phys., 8, 4529-4546, 2008, http://www.atmos-chem-phys.net/8/4529/2008/.

Cantrell, C. A., Stedman, D. H., and Wendel, G. J.: Measurement of atmospheric peroxy radicals by chemical amplification, Anal. Chem., 56, 1496-1502, 1984.

Creasey, D. J., Evans, G. E., Heard, D. E., and Lee, J. D.: Measurements of $\mathrm{OH}$ and $\mathrm{HO}_{2}$ concentrations in the Southern Ocean marine boundary layer, J. Geophys. Res., 108, 4475, doi:10.1029/2002JD003206, 2003.

Dusanter, S., Vimal, D., and Stevens, P. S.: Technical note: Measuring tropospheric $\mathrm{OH}$ and $\mathrm{HO}_{2}$ by laser-induced fluorescence at low pressure. A comparison of calibration techniques, Atmos. Chem. Phys., 8, 321-340, 2008,

http://www.atmos-chem-phys.net/8/321/2008/.

Edwards, G. D., Cantrell, C. A., Stephens, S., Hil, B., Goyea, O., Shetter, R. E., Mauldin, R. L., Kosciuch, E., Tanner, D. J., and Eisele, F. L.: Chemical ionization mass spectrometer instrument for the measurement of tropospheric $\mathrm{HO}_{2}$ and $\mathrm{RO}_{2}$, Anal. Chem., 75, 5318-5327, 2003. 
Finlayson-Pitts, B. J. and Pitts Jr., J. N.: Chemistry of the upper and lower atmosphere, Academic Press, 2000.

Fuchs, H., Hofzumahaus, A., and Holland, F.: Measurement of tropospheric $\mathrm{RO}_{2}$ and $\mathrm{HO}_{2}$ radicals by a laser-induced fluorescence instrument, Rev. Sci. Instr., 79, 084104, doi:10.1063/1.2968712, 2008.

Geyer, A., Bächmann, K., Hofzumahaus, A., Holland, F., Konrad, S., Klüpfel, T., Pätz, H. W., Schäfer, J., and Platt, U.: Nighttime formation of peroxy and hydroxyl radicals during the BERLIOZ campaign: Observations and modeling studies, J. Geophys. Res., 108, 8249, doi:10.1029/2001JD000656, 2003.

Green, T. J., Reeves, C. E., Fleming, Z. L., Brough, N., Rickard, A. R., Bandy, B. J., Monks, P. S., and Penkett, S. A.: An improved dual channel PERCA instrument for atmospheric measurements of peroxy radicals, J. Environ. Monit., 8, 530-536, 2006.

Grosjean, E. and Grosjean, D.: Gas phase reaction of alkenes with ozone: Formation yields of primary carbonyls and biradicals, Environ. Sci. Technol., 31, 2421-2427, 1997.

Grosjean, E., Bittencourt de Andrade, J., and Grosjean, D.: Carbonyl products of the gas-phase reaction of ozone with simple alkenes, Environ. Sci. Technol., 30, 975-983, 1996.

Hanke, M., Uecker, J., Reiner, T., and Arnold, F.: Atmospheric peroxy radicals: ROXMAS, a new mass-spectrometric methodology for the speciated measurements of $\mathrm{HO}_{2}$ and $\sum \mathrm{RO}_{2}$ and first results, Int. J. Mass. Spectrosc., 213, 91-99, 2002.

Hard, T. M., O’Brian, R. J., Chan, C. Y., and Mehrabzadeh, A. A.: Tropospheric free radical determination by FAGE, Environ. Sci. Technol., 18, 768-777, 1984.

Hasson, A. S., Ho, A. W., Kuwata, K. T., and Paulson, S. E.: Production of stabilized Criegee intermediates and peroxides in the gas phase ozonolysis of alkenes: 2. asymmetric and biogenic alkenes, J. Geophys. Res., 106, 34143-34154, 2001.

Hastie, D. R., Weissenmayer, M., Burrows, J. P., and Harris, G. W.: Calibrated chemical amplifier for atmospheric $\mathrm{RO}_{\mathrm{X}}$ measurements, Anal. Chem., 63, 2048-2057, 1991.

Hatakeyama, S., and Kobayashi, H., and Akimoto, H.: Gas-phase oxidation of $\mathrm{SO}_{2}$ in the ozone-olefin reactions, J. Phys. Chem., 88, 4736-4739, 1994.

Heard, D. E. and Pilling, M. J.: Measurement of $\mathrm{OH}$ and $\mathrm{HO}_{2}$ in the Troposphere, Chem. Rev., 103, 5163-5198, 2003.

Hofzumahaus, A. and Holland, F.: Laser-induced fluorescence based detection system for measurement of tropospheric $\mathrm{OH}$ using $308 \mathrm{~nm}$ excitation at low pressure, Proc. SPIE, 1715, 163$173,1993$.

Holland, F., Hofzumahaus, A., Schäfer, J., Kraus, A., and Pätz, H.W.: Measurements of $\mathrm{OH}$ and $\mathrm{HO}_{2}$ radical concentrations and photolysis frequencies during BERLIOZ, J. Geophys. Res., 108, 8246, doi:10.1029/2001JD001393, 2003.

Jenkin, M. E., Saunders, S. M., and Pilling, M. J.: The troposheric degradation of volatile organic compounds: A protocol for mechanism development, Atmos. Environ., 31, 81-104, 1997.

Jenkin, M. E., Saunders, S. M., Wagner, V., and Pilling, M. J.: Protocol for the development of the Master Chemical Mechanism, MCM v3 (Part B): tropospheric degradation of aromatic volatile organic compounds, Atmos. Chem. Phys., 3, 181-193, 2003, http://www.atmos-chem-phys.net/3/181/2003/.

Kanaya, Y., Sadanaga, Y., Nakamura, K., and Akimoto, H.: Development of a ground-based LIF instrument for measuring $\mathrm{HO}_{\mathrm{X}}$ radicals: Instrumentation and calibration, J. Atmos. Chem., 38, 73-110, 2001.

Kanaya, Y., Cao, R., Akimoto, H., Fukuda, M., Komazaki, Y., Yokouchi, Y., Koike, M., Tanimoto, H., Takegawa, N., and Kondo, Y.: Urban photochemistry in central Tokyo: 1. observed and modeled $\mathrm{OH}$ and $\mathrm{HO}_{2}$ radical concentrations during the winter and summer 2004, J. Geophys. Res., 112, D06301, doi:10.1029/2007JD008670, 2007.

Karl, M., Brauers, T., Dorn, H.-P., Holland, F., Komenda, M., Poppe, D., Rohrer, F., Rupp, L., Schaub, A., and Wahner, A.: Kinetic study of the $\mathrm{OH}$-isoprene and $\mathrm{O}_{3}$-isoprene reaction in the atmosphere simulation chamber SAPHIR, Geophys. Res. Lett., 31, L05117, doi:10.1029/2003GL019189, 2004.

Mihelcic, D., Müsgen, P., and Ehhalt, D. H.: An improved method of measuring tropospheric $\mathrm{NO}_{2}$ and $\mathrm{RO}_{2}$ by matrix isolation and electron spin resonance, J. Atmos. Chem., 3, 341-361, 1985.

Mihelcic, D., Volz-Thomas, A., Pätz, H. W., Kley, D., and Mihelcic, M.: Numerical analysis of ESR spectra from atmospheric samples, J. Atmos. Chem., 11, 271-297, 1990.

Mihelcic, D., Holland, F., Hofzumahaus, A., Hoppe, L., Müsgen, P., Pätz, H. W., and Moortgat, G. K.: Peroxy radicals during BERLIOZ at Pabstthum: Measurements, radical budgets and ozone production, J. Geophys. Res., 108, 9-1, 2003.

Mihele, C. M. and Hastie, D. R.: The sensitivity of the radical amplifier to ambient water vapor, Geophys. Res. Lett., 25, 19111913, 1998.

Monks, P. S.: Gas-phase radical chemistry in the troposphere, Chem. Soc. Rev., 34, 376-395, 2005.

Olzman, M., Kraka, E., Cremer, D., Gutbrod, R., and Andersson, S.: Energetics, kinetics and product distributions of the reactions of ozone with ethene and 2.3-dimethyl-2-butene, J. Phys. Chem. A, 101, 9421-9429, 1997.

Platt, U., Alicke, B., Dubois, R., Geyer, A., Hofzumahaus, A., Holland, F., Martinez, M., and Stutz, J.: Free radicals and fast photochemistry during BERLIOZ, J. Atmos. Chem., 42, 359-394, 2002.

Press, W. H., Teukolsky, S. A., Vetterling, W. T., and Flannery, B. P.: Straight-line data with errors in both coordinates, in: Numerical recipies in C, Cambridge University Press, Cambridge, 666-670, 1992.

Qi, B., Takami, A., and Hatakeyama, S.: A calibration method for measurement of small alkyl organic peroxy radicals by chemical amplifier, Anal. Sci., 22, 1091-1093, 2006.

Reichert, L., Andrés Hernández, M. D., Stöbener, D., Burkert, J., and Burrows, J. P.: Investigation of the effect of water complexes in the determination of peroxy radical ambient concentrations: Implications for the atmosphere, J. Geophys. Res., 108, 4017, doi:10.1029/2002JD002152, 2003.

Reiner, T., Hanke, M., and Arnold, F.: Atmospheric peroxy radical measurement by ion molecule reaction-mass spectroscopy: A novel analytic method using amplifying chemical conversion to sulfuric acid, J. Geophys. Res., 102, 1311-1326, 1997.

Ren, X., Edwards, G. D., Cantrell, C. A., Lesher, R. L., Metcalf, A. R., Shirley, T., and Brune, W. H.: Intercomparison of peroxy radical measurements at a rural site using laser-induced fluorescence and peroxy radical chemical ionization mass spectrometer (PerCIMS) techniques, J. Geophys. Res., 108, 4605, doi:10.1029/2003JD003644, 2003. 
Rohrer, F., Bohn, B., Brauers, T., Brüning, D., Johnen, F.-J., Wahner, A., and Kleffmann, J.: Characterisation of the photolytic HONO-source in the atmosphere simulation chamber SAPHIR, Atmos. Chem. Phys., 5, 2189-2201, 2005, http://www.atmos-chem-phys.net/5/2189/2005/.

Sander, S. P., Friedl, R. R., Golden, D. M., Kurylo, M. J., Moortgart, G. K., Keller-Rudek, H., Wine, P. H., Ravishankara, A. R., Kolb, C. E., Molina, M. J., Finlayson-Pitts, B. J., Huie, R. E., and Orkin, V. L.: Chemical kinetics and photochemical data for use in atmospheric studies, NASA JPL Publication, 06-2, 2006.

Schlosser, E., Bohn, B., Brauers, T., Dorn, H., Fuchs, H., Häseler, R., Hofzumahaus, A., Holland, F., Rohrer, F., Rupp, L. O., Siese, M., Tillmann, R., and Wahner, A.: Intercomparison of two hydroxyl radical measurement techniques at the atmospere simulation chamber SAPHIR, J. Atmos. Chem., 56, 187-205, 2007.
Schultz, M., Heitlinger, M., Mihelcic, D., and Volz-Thomas, A.: Calibration source for peroxy radicals with built-in actinometry using $\mathrm{H}_{2} \mathrm{O}$ and $\mathrm{O}_{2}$ photolysis at $185 \mathrm{~nm}$, J. Geophys. Res., 100, 18811-18816, 1995.

Stevens, P. S., Mather, J. H., and Brune, W. H.: Measurement of tropospheric $\mathrm{OH}$ and $\mathrm{HO}_{2}$ by laser-induced fluorescence at low pressure, J. Geophys. Res., 99, 3543-3557, 1994.

Wegener, R., Brauers, T., Koppmann, R., Rodríguez Bares, S., Rohrer, F., Tillmann, R., Wahner, A., Hansel, A., and Wisthaler, A.: Simulation chamber investigation of the reactions of ozone with short-chained alkenes, J. Geophys. Res., 112, D13301, doi:10.1029/2006JD007531, 2007. 